\title{
BIBLIOGRAFÍA SOBRE TEMAS ÁRABES DE SHARO AL-ANDALUS (Levante de Al-Andalus)
}

\author{
Por \\ MIKELL DE EPALZA \\ FRANCISCO FRANCO SÁNCHEZ
}

Esta bibliografía constituye un segundo apéndice al libro de Míkel de Epalza, J. M. Paternina y A. Couto, Moros y moriscos en el Levante peninsular. Introducción bibliográfica, Alicante, Instituto de Estudios Alicantinos, 1983, y continuación del apéndice de Míkel de Epalza y Francisco Franco Sánchez, con este mismo título, en Sharq Al-Andalus. Estudios Arabes, Alicante, núm. 1 , 1984, pp. 213-248. Son válidas las mismas observaciones que se hicieron en el prólogo del libro $y$ la presentación del articulo.

Aquí se recogen 259 títulos nuevos, sin ninguna pretensión a la exhaustividad. Sólo se trata de novedades. El rastreo exhaustivo se realizará de nuevo más adelante. Se agradece una vez más a las colaboraciones, pasadas y futuras, con la persuasión de que esta labor bibliográfica puede ser útil instrumento de trabajo para el investigador, contribuye a elevar el nivel científico de estas investinaciones y constituye un patente testimonio del interés, la variedad y la abundancia de estudios sobre temas árabes en esta región.

A

2.550 - AGUILAR, J.; MUT, F., "Cullera. Castillo", Catálogo de monumentos y conjuntos de la Comunidad Valenciana, Valencia, Consellería de Cultura de la Generalitat, vol. I, 1983, pp. 345-350.

2.551 - AGUILAR, J.; MUT, F., "Gandía. Morabito", Catálogo de monumentos y conjuntos de la Comunidad Valenciana, Valencia, Consellería de Cultura de la Generalitat, vol. I, 1983, pp. 444-447.

2.552 - AGUILÓ. P., "Castillo de Sagunto", Catálogo de monumentos y conjuntos de la Comunidad Valenciana, Valencia, Consellería de Cultura de la Generalitat, vol. II, 1983, pp. 121-126.

2.553 - ALFONSO, M. ${ }^{a}$ D., "Cofrentes. Castillo", Catálogo de monumentos y conjuntos de la Comunidad Valenciana, Valencia, Consellería de Cultura de la Generalitat, vol. I, 1983, pp. 340-345. 
2.554 - AL-HARRĀS, 'Abd As-Salām, "Intāŷ Ibn Al-Abbär Al-Balansī», Revista del Instituto Egipcio de Estudios Islámicos en Madrid, Madrid, XXII, 1983-1984, pp. 105-116. Resumen de tesis doctoral sobre la producción escrita de este historiador $\vee$ político valenciano del siglo XIII, Ibn Al-Abbār.

2.555 - ALVENTOSA GARCIA, Rafael, Geografia e Historia de Beniganim, Játiva, s. a. (h. 1950).

2.556 - ALVENTOSA GARCIA, Rafael, Geografía e Historia de Quesa, Játiva, s. a. (h. 1950).

2.557 - AMADOR DE LOS RIOS, Rodrigo, "Fragmentos de lápida sepulcra arábiga hallado en Alcoy (Alicante)", Revista de Archivos, Bibliotecas y Museos, Madrid, núm. 4, 1900, pp. 712-714.

2.558 - ASIN PALACIOS, Miguel, L'slam Christianisé. Étude sur le soufisme d'Ibn 'Arabi de Murcie, París, Editions de la Maisnie, 1982

2.559 - ASIN PALACIOS, Miguel, "El lulismo exagerado", Cultura Española, Madrid, 1906.

2.560 - ASIN PALACIOS, Miguel, "La psicología del éxtasis en los dos grandes místicos musulmanes: Algazel y Abenarabín, Cultura Española, Madrid, 1906.

2.561 - ASÍN PALACIOS, Miguel, "La psicología, según Mohidín Abenarabí», Actes du XIV. ${ }^{*}$ Congrés International des Orientalistes, París, Lerous, vol. Ili, 1907, pp. 79-191.

2.562 - AZUAR RUIZ, Rafael, "Alicante. Castillo y Fortaleza de Santa Bárbaran, Catálogo de Monumentos y Conjuntos de la Comunidad Valenciana, Valencia, Consellería de Cultura de la Generalitat, vol. I, 1983. páginas 83-93.

2.563 - AZUAR RUIZ, Rafael, "Biar. Castillo-fortaleza», Catálogo de Monumentos y Conjuntos de la Comunidad Valenciana, Valencia, Consellería de Cultura de la Generalitat, vol. I, 1983, pp. 190-198.

2.564 - AZUAR RUIZ, Rafael, "Elche. Palacio de Altamira", Catálogo de Monumentos y Conjuntos de la Comunidad Valenciana, Valencia, Consellería de Cultura de la Generalitat, vol. I, 1983, pp. 405-409.

2.565 - AZUAR RUIZ, Rafael, "Elche. Torre de la Calahorra», Catálogo de Monumentos y Conjuntos de la Comunidad Valenciana, Valencia, Consellería de Cultura de la Generalitat, vol. 1, 1983, pp. 420-423.

2.566 - AZUAR RUIZ, Rafael, "Novelda. Castillo de la Mola", Catálogo de Monumentos y Conjuntos de la Comunidad Valenciana, Valencia, Consellería de Cultura de la Generalitat, vol. I, 1983, pp. 572-576.

2.567 - AZUAR RUIZ, Rafael, "Orihuela. Castillo", Catálogo de Monumentos y Conjuntos de la Comunidad Valenciana, Valencia, Consellería de Cultura de la Generalitat, vol. I, 1983, pp. 665-671.

2.568 - AZUAR RUIZ, Rafael, "Petrel. Castillo-fortaleza", Catálogo de Monumentos y Conjuntos de la Comunidad Valenciana, Valencia, Consellería de Cultura de la Generalitat, vol. II, 1983, pp. 31-38.

2.569 - AZUAR RUIZ, Rafael, "La portada interior de la "Torre del Mig" de la Alcazaba de Denian, Sharq Al-Andalus. Estudios Arabes, Alicante, número 1, 1984, pp. 123-131. 
2.570 - AZUAR RUIZ, Rafael, "Villena. Castillo y fortaleza de la Atalaya", Catálogo de Monumentos y Conjuntos de la Comunidad Valenciana, Valencia, Consellería de Cultura de la Generalitat, vol. It, 1983, páginas 877-884.

B

2.571 - BALAÑA I ABADIA, Pere, "Sobre els mots catalans del tipus "ll-" procedents de l'àrab. Avançament d'una possible "regularitat" etimoldgican, Societat d'Onomàstica. Butl/et' Interior. IX Col.loqui de Tarragona (13-14/VII/1984), Barcelona, XVII, set. 1984, pp. 45-51.

2.572 - BARCELÓ PERELLO, Miquel, "Las Islas Orientales de Al-Andalus, formación y destrucción de una sociedad musulmana (902-1229), Historia de los pueblos de España. Vol. I. Los antiguos territorios de la Corona de Aragón, Barcelona, Argos Vergara, 1984, pp. 101-115.

2.573 - BARCELÓ PERELLÓ, Miquel, "Visigodos y árabes en el proceso de formación de Cataluña". Historia de los pueblos de España. Vol. l. Los antiguos territorios de la Corona de Aragón. Barcelona, Argos Vergara, 1984, pp. 215-225.

2.574 - BARCELÓ TORRES, María del Carmen, "Almoixàvena y arnadí de la cocina árabe a la valencianan, Xàtiva. Fira d'Agost, 1984, Játiva, 1984, pp. 61-63.

2.575 - BARCELÓ, Carmen; LABARTA, Ana, "Azúcar, "trapigs" y dos textos árabes valencianos", Sharq Al-Andalus. Estudios Arabes, Alicante, núm. 1, 1984, pp. 55-71.

2.576 - BARCELÓ TORRES, Carme, "Bellreguard", Ullal, Gandía, núm. 2, 1982, pp. 65-66. Refuta etimología árabe del artículo de Torres Cremades.

2.577 - BARCELÓ TORRES, María del Carmen, Minorías istámicas en el Pais Valenciano. Historia y dialecto, Valencia, Universidad de ValenciaInstituto Hispano-Árabe de Cultura, 1984, 400 páginas.

2.578 - BARCELO TORRES, Maria del Carmen, «Precisiones sobre algunos arabismos en valenciano y otros nuevos", Quaderns de Filologia. Miscel.lània Sanchis Guarner, Valencia, I, 1984, pp. 25-28.

2.579 - BARCELÓ TORRES, Carmen, Toponimia arábica del País Valencià. Alqueries $i$ castells, Canals (Valencia), 1983, XVIII + 307 páginas.

2.580 - BEGUER ESTEVE, Vicente, "Torrent en l'expuisió dels moriscs", Cronicó del Regne de València, núms. 9-10, gener-septembre 1980, página 16.

2.581 - BELDA SOLER, María de los Ángeles, Aportación a la historia de Ayelo de Malferit, Valencia, 1982.

2.582 - BENTO GOERLICH, D., "Valencia. Baños del Almirante", Catálogo de Monumentos y Conjuntos de la Comunidad Valenciana, Valencia, Consellería de Cultura de la Generalitat, vol. II, 1983, pp. 387-390.

2.583 - BENET, Plácido, "El tribunal de las aguas de Valencia ¿una herencia árabe?, Tigris, Madrid, 31 de enero de 1985, pp. 40-45. Artículo de divulgación. El día musulmán no empieza al mediodía, sino al ponerse el sol. 
2.584 - BEUT I BELENGUER, Emili, "Castells valencians", Crónica de la XII Asamblea de Cronistas del Reino de Valencia, 1980, pp. 271-280.

2.585 - BEVIÀ, Màrius, "L'albacar musulmà del castell d'Alacant", Sharq A/Andalus. Estudios Arabes, Alicante, núm. 1, 1984, pp. 131-141.

2.586 - BOIGUES, Carlos, "L'arquitectura hidràuliça. Els molins d'aigua en la Vall de Gallinera", "/ Congrés d'Estudis de la Marina Alta, Denia, 1984 (en prensa).

2.587 - BOIGUES, Carlos; SOLAZ, Victoria, «La arquitectura militar hispanomusulmana en la Vall de Gallinera», / Congrés d'Estudis de la Marina Alta, Denia, 1983 ien prensal.

2.588 - BURNS, Robert Ignatius, "Los mudéjares de la Valencia de las Cruzadas: un capítulo olvidado de la historia islámica", Sharq Al-Andalus. Estudios Árabes, Alicante, núm. 1. 1984, pp. 15-35.

\section{C}

2.589 - CABRILLANA, Nicolás, Almería morisca, Granada, Universidad, 1982,332 páginas.

2.590 - CALDUCH, Joan, "Alicante. Conjunto sector antiguo, Isla de Tabarcan, Catálogo de Monumentos y Conjuntos de la Comunidad Valenciana, Valencia, Consellería de Cultura de la Generalitat, vol. I, 1983, páginas 60-83.

2.591 - CAMPANER, Alvaro, "Bosquejo histórico de la dominación islamita en las Islas Baleares", Estudios críticos de Historia árabe-española, Zaragoza-Madrid, 1903-1917 (vol. VII de la Colección de Estudios Arabes).

2.592 - CARBONERO, María Antonia, "Terrasses per al cultiu irrigat i distribució social de l'aigua a Benyalbufar (Mallorca)", Documents d'Anàlisi Geogràfic, Bellaterra, núm. 4, 1984, pp. 31-68. Métodos de captación de agua de época árabe.

2.593 - CARMONA GONZÁLEZ, Alfonso, "Al-Qartāŷanī, un poeta arábigo-españoli, La traducción: arte y técnica. Nueva revista de enseñanzas medias, Madrid, núm. 6, pp. 155-157.

2.594 - CARMONA GONZÁLEZ, Alfonso, «Murcia, ¿una fundación árabe? (Historiografía de una polémica)», Miscelánea Medieval Murciana, Murcia, XI, 1984, pp. 11-65.

2.595 - CARRASCO, Rafael, "Le refus d'assimilation des Morisques: aspects politiques et culturels d'après les sources inquisitoriales", Les Morisques et leur temps. París, 1984, pp. 169-216.

2.596 - Catálogo de Monumentos y Conjuntos de la Comunidad Valenciana, Valencia, Consellería de Cultura, Educación y Ciencia de la Generalitat Valenciana, 1983, 2 volúmenes.

2.597 - CHABÁS, Roque; RIBERA, Julián; PONS BOIGUES, Francisco, "Textos sobre Alcira y Játiva árabes", Shàrq Al-Andalus. Estudios Arabes, Alicante, núm. 1, 1984, pp. 185-199.

2.598 - LA CHICA GARRIDO, Margarita, "La "lawha" de Castalla", Sharq A/Andalus. Estudios Árabes, Alicante, núm. 1, 1984, pp. 153-161. 
2.599 - CISCAR PALLARÉS, E., "El destino de los bienes inmuebles de los moriscos y su incidencia en el debate sobre la disolución de los señoríos", Estudis, Valencia, núm. 8, 1982, pp. 167-176.

2.600 - CLAVER CORTÉS, María del Carmen, "El proceso repoblador tras la expulsión de los moriscos en el señorío de Relleu", Anales de la Universidad de Alicante. Historia Moderna, Alicante, núm. 4, 1984, páginas, 417-429.

2.601 - CODERA Y ZAIDÍN, Francisco, "Conquista de Aragón y Cataluña por los musulmanesm, Estudios Críticos de Historia árabe-española, Zaragoza-Madrid, 1903-1917 (vol. VIl de la Colección de Estudios Árabes).

2.602 - CODERA Y ZAIDIN, Francisco, "La dominación arábiga en la Frontera Superior, o sea, poco más o menos, en la cuenca del Ebro y en la Galia meridional, años 711 a 815 ", Estudios Críticos de Historia árabeespañola, Zaragoza-Madrid, 1903-1917 (vol. VIII de la Colección de Estudios Árabes).

2.603 - CODERA Y ZAIDIN, Francisco, «Importancia general que tiene para España el estudio de la lengua árabe y en especial para los que han nacido en el antiguo Reino de Aragón:m. Estudios críticos de historia árabe-española, Zaragoza-Madrid, 1903-1917 (vol. VIll de la Colección de Estudios Árabes).

2.604 - CODERA Y ZAIDIN, Francisco, "Límites probables de la conquista árabe en la cordillera pirenaican, Estudios Críticos de Historia arabe-española, Zaragoza-Madrid, 1903-1917 (vol. VIII de la Colección de Estudios Arabes).

2.605 - CODERA Y ZAIDIN , Francisco, "Mohámed Atauil, rey moro de Huescan, Estudios Críticos de Historia d́rabe-española, Zaragoza-Madrid, 1903-1917 (vol. VIl de la Colección de Estudios Árabes).

2.606 - CODERA Y ZAIDIN, Francisco, "Narbona, Gerona y Barcelona bajo la dominación musulmanan, Estudios Críticos de Historia árabe-española, Zaragoza-Madrid, 1903-1917 (vol. VIll de la Colección de Estudios Árabesi.

2.607 - CODERA Y ZAIDÍN, Francisco, «Noticias acerca de los Benihud, reves de Zaragoza, Lérida, Calatayud y Tudelan, Estudios Críticos de Historia árabe-española, Zaragoza-Madrid, 1903-1917 (vol. Vil de la Colección de Estudios Árabesl.

2.608 - CODERA Y ZAIDÍN, Francisco, "Otras rectificaciones. Condado de Aragón, Ampurias y Barcelona en el año 848. Los Benimuzan, Estudios Criticos de Historia árabe-española, Zaragozamadrid, 19031917 (vol. VIl de la Colección de Estudios Árabes).

2.609 - CORRIENTE, Federico, "Nuevas apostillas de lexicografía hispanoárabe lal margen del Diccionari etimologic i complementari de la llengua catalana, de Joan Coromines)", Sharq Al-Andalus. Estudios Arabes, Alicante, núm. 1, 1984, pp. 7-15.

be lal margen del Diccionari etimológic i complementari de la llengua catalana, de Joan Corominesin, Sharq Al-Andalus. Estudios Árabes, Alicante, núm. 1, 1984, pp. 7-15. 
2.611 - CORRIENTE, Federico, "Precisiones etimológicas a "bassetja" y "baldraca"', Anuario de Filologia, Barcelona, núm. 8, 1982, pp. 105-109. Dos palabras catalanas de origen árabe.

2.612 - CRESPI, G., Los árabes en Europa, introducción de F. Gabrielli, Madrid, ed. Encuentro, 1982, 353 páginas.

2.613 - CURTO, Albert; LORIENTE, Ana; MARTINEZ LANDIN, Charo; ROS, Elisa, "Excavacions al castell de La Suda de Tortosa", Sharq Al-AndaIus. Estudios Árabes, Alicante, núm. 1, 1984, pp. 141-147.

2.614 - DALMASES, N.; PITARCH, A. J., "Onda. Casco antiguo de la villa", Catálogo de Monumentos y Conjuntos de la Comunidad Valenciana, Valencia, Consellería de Cultura de la Generalitat, vol. I, 1983, páginas 602-616.

\section{$E$}

2.615 - EPALZA, Míkel de, "Africanismo nuevo y viejo en España: un coloquio en la U. N. E. D. de Madrid", Anales de Historia Contemporánea, Murcia-Orihuela, núm. 3, 1984, pp. 269-271.

2.616 - EPALZA, Míkel de, "Alguns aspectes de la morofília literària actual al País Valenciàn, Sharq Al-Andalus. Estudios Árabes, Alicante, núm. 1 , 1984, pp. 169-173.

2.617 - EPALZA, Míkel de, «Dos textos moriscos bilingües (árabe y castellano) de viajes a Oriente (1395 y 1407-1412)», Hespéris-Tamuda, Rabat, $X X-X X I, 1982-83$, pp. 25-112

2.618 - EPALZA, Míkel de, "Los beréberes y la arabización del País Valenciano", Quaderns de Filología. Miscel.lània Sanchis Guarner, Valencia, núm. 1, 1984, pp. 91-100.

2.619 - EPALZA, Míkel de; FRANCO SÁNCHEZ, Francisco, "Bibliografía sobre temas árabes de Sharq Al-Andalus (Levante de Al-Andalus)», Sharq Al-Andalus. Estudios Árabes, Alicante, núm. 1, 1984, pp. 213-249.

2.620 - EPALZA, Míkel de, uUn cuaderno de aprender árabe, en Elche, de $1768 n$, Sharq Al-Andalus. Estudios Árabes, Alicante, núm. 1, 1984, páginas 167-169.

2.621 - EPALZA, Míkel de, "Funciones ganaderas de los albacares, en las fortalezas musulmanas", Sharq Al-Andalus. Estudios Arabes, Alicante, núm. 1, 1984, pp. 47-55.

2.622 - EPALZA, Míkel de, "L'identité onomastique et linguistique des Morisques", Religion, Identité et Sources Documentaires sur les Morisques Andalous, Túnez, 1984, partie française, espagnole et anglaise, volumen I, páginas 269-279.

2.623 - EPALZA, Míkel de, «Dos literatos árabes viajan por Sharq Al-Andalus: Shakib Arslán (1939) y Husáin Mones (1963)", Sharq Al-Andalus. Estudios Árabes, Alicante, núm. 1, 1984, pp. 173-185. 
2.624 - EPALZA, Mikel de, "Le milieu hispano-moresque de l'évangile islamisant de Barnabé (XVI. $\left.{ }_{-}-X V \mid l 1 .{ }^{\circ}\right)$, Islamochristiana, Roma, núm. 8, 1982, pp. 159-183.

2.625 - EPALZA, Mikel de, «El primer tratado de paz hispano-libio de 1784 11198 Hégira)n, Hispania, Madrid, 157, 1984, pp. 277-319.

2.626 - EPALZA, Míkel de, "Propuestas para un centenario hispano-árabe (1492-1992) len árabe), Al Karmel, Nicosia, 12, 1984, páginas $111-115$.

2.627 - ESCRIVÁ, Vicent, "Jacob Xalabín: complex de cultura i el narrador", Quaderns de Filologia. Miscel.Jània Sanchis Guarner, Valencia, I, 1984, pp. 101-105. Novela en catalán de tema turco, del siglo XIV, con glosario de turquismos y arabismos.

2.628 - ESPI RAEL, Joaquin, «El barrio mozárabe de San Cristóbal», Almanaque de la Asociación de San José de Calasanz, Lorca, 1930, páginas 83-89. Noticia del barrio lorquino en 1497

2.629 - ESTAL, Juan Manuel del, El Reino de Murcia bajo Aragón (12961305/. Corpus documenta///1., Alicante, Instituto de Estudios «Juan Gil Albert", 1985, 474 páginas. Numerosos documentos referentes a musulmanes y a paises musulmanes.

\section{$\mathbf{F}$}

2.630 - FERNANDEZ MORÁN, Juan A., Contribución a la identificación de an. tropónimos árabes en el Repartimiento de Valencia, Barcelona, Universidad, Memoria de Licenciatura del Departamento de Árabe, 19 de septiembre de 1984.

2.631 - FURIÓ, Antoni; GARCÍA, Ferrán, «Algunas consideraciones acerca del feudalismo medieval valencianon. Estudios sobre historia de España. Homenaje a Tuñón de Lara, vol. 1, 1981, pp. 109-122. La conquista por Jaime I del futuro Reino de Valencia, la reorganización y asentamiento de los conquistadores y los cambios sociales que el fenómeno conllevó.

\section{G}

2.632 - GAILLARD, Georges, "La Catalogne entre I'art de Cordoue et l'art roman: Influences musulmanes sur l'art préroman en Catalognen, Studia Islamica, París, fasc. VI, 1956, pp. 19-35.

2.633 - GALMÉS DE FUENTES, Ávaro, "Etomología árabe del topónimo "Manacor" (Mallorca)", Quaderns de Filologia. Miscel.lània Sanchis Guarner, Valencia, 1, 1984, pp. 125-127.

2.634 - GARCÍA, Ferrán; LA PARRA, Santiago, "Documents per a una història de la Saforn, Ullal, Gandía, 4, 1983, pp. 94-106. Texto de disputa de un musulmán de Taverna, de 1514 , y otro del Duque de Gandía a Felipe III, sobre expulsión de moriscos. 
2.635 - GARCIA ARENAL, Mercedes, "Cristianos, moros y judíos en la época de Alfonso X", Catálogo de la exposición "Alfonso X. Toledo, 1984», Toledo, 1984, pp. 31-47.

2.636 - GARCIAA ARENAL, Mercedes, "Últimos estudios sobre moriscos: Estado de la cuestión", Al-Qantara, Madrid, IV, 1983, pp. 101-115.

2.637 - GARCIA CÁRCEL, Ricardo, “La Inquisición y los moriscos», en J.PÉREZ VILLANUEVA..., Historia de la Inquisición, vol. I, pp. 901-913. En especial, estudio de las actividades de Felipe III y el Patriarca Ribera en Valencia.

2.638 - GARCIA CÁRCEL, Ricardo, "Valencia en los siglos XV y XVI", Historia de los pueblos de España. Vol. l. Los antiguos territorios de la Corona de Aragón, Barcelona, Argos Vergara, 1984, pp. 419-436. Referencia a los moriscos y la Inquisición.

2.639 - GARCÍA LISÓN, M.; ZARAGOZÁ, A., "Peñíscola. La ciudad. Castillo y palacion, Catálogo de Monumentos y Conjuntos de la Comunidad Valenciana, Valencia, Consellería de Cultura de la Generalitat, vol. II, 1983, pp. 14-30.

2.640 - GEFAELL, María Luisa, El Cid, Barcelona, ed. Noguer, 1965, 136 páginas. Libro divulgativo para los niños, con abundantes ilustraciones.

2.641 - GÓMEZ MORENO, M., Iglesias mozárabes. Arte español de los siglos IX-XI, Madrid, 1919.

2.642 - GONZÁleZ BALDOVÍ, M., "Montesa. Castillo", Catálogo de Monumentos y Conjuntos de la Comunidad Valenciana, Valencia, Consellería de Cultura de la Generalitat, vol. 1, 1983, pp. 521-531.

2.643 - GONZÁLEZ BALDOVI, M., "Xàtiva. Conjunto histórico-artístico de la Villa de Xàtivan, Catálogo de Monumentos y Conjuntos de la Comunidad Valenciana, Valencia, Consellería de Cultura de la Generalitat. vol. II, 1983, pp. $911-924$

2.644 - GONZÁLEZ PALENCIA, A., Rectificación de la mente. Tratado de Lo. gica, por Abusalt de Denia. Texto árabe, traducción y estudio previo, Madrid, 1915.

2.645 - GREGORI MAYAR, Salvador, "Historia de la inseguridad ciudadana en Callosan, Festes de Moros i Cristians, Callosa d'En Sarrià, 1984, 6 páginas. Al-Azraq, germanías, argelinos, expulsión de los moriscos.

2.646 - GUICHARD, Pierre, "L'eau dans le monde musulman médieval», L'homme et l'eau en Méditerranée et au Proche-Orient, II. Aménagements hydrauliques, états et législation, Lyon, Presses Universitaires de Lyon, 1982, pp. 117-124

2.647 - GUICHARD, Pierre, "El problema de la existencia de estructuras de tipo "feudal" en la sociedad de Al-Andalus (el ejemplo de la región valenciana)", Estructuras feudales y feudalismo en el mundo mediterráneo, Barcelona, Editorial Crítica, 1984, pp. 117-145.

2.648 - GUICHARD, Pierre, "La región valenciana del siglo VIII al XIV", Historia de los pueblos de España. Vol. I. Los antiguos territorios de la Corona de Aragón, Barcelona, Argos Vergara, 1984, pp. 387-417. 
2.649 - HEGYI, O., Cinco leyendas y otros relatos moriscos ims. 4953 de la Biblioteca Nacional de Madrid), Madrid, ed. Gredos, 1981, 382 pp., Col. Literatura Española Aljamiado-Morisca.

2.650 - HERRERO ALONSO, Abelardo, Aportaciones a la toponimia de la Conca de la Safor, Gandia, Instituto Duque Real Alonso El Viejo, 1983, $171 \mathrm{pp}$. Diversos topónimos árabes, algunos de antes de la expulsión de los moriscos.

2.651 - HERRERO HERRERO, Valeriano, La Villa de Alpuente. (Aportación al conocimiento de un pueblo con historia), Segorbe (Castellón), Valeriano Herrero ed., 1978, $230 \mathrm{pp}$.

2.652 - HINOJOSA MONTALVO, José, "Mudéjares granadinos en el Reino de Valencia a fines del siglo XV (1484-1492), La Sociedad Medieval Andaluza: Grupos no privilegiados. Actas del III Coloquio de Historia Medieval Andaluza, Jaén, 1984, pp. 121-130.

2.653 - HURTADO, V.; PENARROCHA, j.; SANCHA, J. M.; TOMÁS, J. M., "Ontinyent. Barrio antiguo de la Villa". Catálogo de Monumentos y Conjuntos de la Comunidad Valenciana, Valencia, Consellería de Cultura, vol. 1, 1983, pp. 625-641.

2.654 - IVARS PÉREZ, Josep, La ciutat de Dénia. Evolució i permanència del fet urbà, Alicante, Caja de Ahorros Provincial, 1982.

2.655 - IVARS PÉREZ, Josep, "Notas para una posible actuación arqueológica en los cascos de la Marina Alta", Il Congrés d'Estudis de la Marina Alta, Denia, 1984 (en prensa).

2.656 - IVARS PÉREZ, Josep; DOMÉNECH, Jaume, "Molins d'aigua a la conca del Girona", /l Congrés d'Estudis de la Marina Alta, Denia, 1984 (en prensa).

2.657 - IVARS PÉREZ, Josep, "Uurbanisme islàmic a Ondara», Libro de Fiestas de Ondera, Ondara, 1983.

2.658 - IVARS PÉREZ, Josep: "Urbanisme musulmá y gòtic a la Marina Alta”, I Congrés d'Estudis de la Marina Alta, Denia, 1983 (en prensal.

2.659 - IVARS PÉREZ, Josep, «Urbanismo y sociedad en la Denia del 300. La formación de una ciudad medieval. La Villa de Denia", Dianium, Revista Universitaria de las Letras y las Ciencias, Denia, núm. 2, 1983, páginas 333-357.

2.660 - IVARS PÉREZ, Josep, "Unas viviendas moriscas en la Cairola LLa Vall d'Ebol", Sharq Al-Andalus. Estudios Arabes, Alicante, núm. 1, 1984, pp. 91-103.

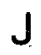

2.661 - JAÉN, Gaspar, "Elche. Sector antiguo de la ciudad", Catálogo de Monumentos y Conjuntos de la Comunidad Valenciana, Valencia, Consellería de Cultura de la Generalitat, vol. 1, 1983, pp. 385-391.

2.662 - JUSTEL CALABOZO, Braulio, "El "Vocabulista" de Alcalá y su refundición por Patricio de la Torren, Sharq Al-Andalus. Estudios Árabes, Alicante núm. 1, 1984, pp. 35-47. 
2.663 - LABARTA, Ana, "Supersticiones moriscas", Awraq, Madrid, númerós 5-6, 1982-83, pp. 161-191.

2.664 - LAFUENTE NIÑO, I., "Requena. Barrio de la Villa (Recinto medieval"", Catálogo de Monumentos y Conjuntos de la Comunidad Valenciana, Valencia, Consellería de Cultura de la Generalitat, vol. Il, 1983, páginas 74-89.

2.665 - LILLO CARPIO, Pedro A., "Las planchas monetales de Cieza y su posible relación con el Khatam islámicon, Anales de la Universidad de Murcia, Murcia, XLIII/3-4, 1984.

2.666 - LLOBREGAT, Enrique A., "La geografia antiga valenciana i l'Anònim de Ravenna: notes de lectura", L'Espill, Valencia, 17-18, 1983, páginas 99-111.

2.667 - LLOBREGAT, Enrique A., «La perduración de un topónimo de la Vía Augusta: Lubricatum / Rahal al-Lobregati / Turris de Lupricaton, Sharq Al-Andalus. Estudios Arabes, Alicante, núm. 1, 1984, pp. 103-109.

2.668 - LLOMPART, Gabriel, "Testamentos de mercaderes mallorquines rogados entre musulmanes (1374-1388), Hispania, Madrid, 157. 1984, pp. 411-431.

2.669 - LLUCH ARNAL, Emilio, El señorío v baronía de Náquera Imecanografiada-offset), 1983.

2.670 - LOPEZ ELUM, Pedro, "Bétera. Casa-castillo", Catálogo de Monumentos y Conjuntos de la Comunidad Valenciana, Valencia, Consellería de Cultura de la Generalitat, vol. I, 1983, pp. 187-190.

2.671 - LÓPEZ ELUM, Pedro, "El Castillo de Xàtiva désde la perspectiva de un estudio archivístico-arqueológicon, Xàtiva. Fira d'Agost, 1984, Játiva 1984, pp. 73-76.

2.672 - LÓPEZ ELUM, Pedro, "Paterna. Torre árabe y cuevas que la circundan", Catálogo de Monumentos y Conjuntos de la Comunidad Valenciana, Valencia, Consellería de Cultura de la Generalitat, vol. II, 1983, pp. 6-13.

2.673 - LÓPEZ ELUM, Pedro, "Quart de Poblet. Cisterna árabe», Catálogo de Monumentos y Conjuntos de la Comunidad Valenciana, Valencia, Consellería de Cultura de la Generalitat, vol. II, pp. 65-69.

2.674 - LÓPEZ ELUM, Pedro, "Silla. Torre musulmana», Catálogo de Conjuntos y Monumentos de la Comunidad Valenciana, Valencia, Consellería de Cultura de la Generalitat, vol. 11, 1984, pp. 173-177.

\section{M}

2.675 - MARCO, Mateo, "Llanto y casida de un poeta alicantino por el exilio del rey moro de Sevillan, Aljibe, Villena, noviembre 1984, pp. 42-46.

2.676 - MARTIN VELASCO, M., "Sagunto. La villa de Sagunto: zona antigua", Catálogo de Monumentos y Conjuntos de la Comunidad Valenciana, Valencia, Conselleria de Cultura de la Generalitat, vol. II, 1983, páginas 103-120. 
2.677 - MARTÍNEZ BALDO, Ángel; SICLUNA LLETGET, Ricardo; SBERT, Toni, "Xàtiva: evolució urbana", Papers de la Costera, Xàtiva, 2, 1983. pp. 79-82. Urbanismo de Játiva musulmana.

2.678 - MARTINEZ MONTOYA, Manuel, Recuerdos africanos, Crevillente, $1983,97 \mathrm{pp}$. Recuerdos de un voluntario de Crevillente en la guerra de Sidi Ifni (Marruecos), en 1957-59.

2.679 - MAS, María P., «Valencia. Torre adosada al lienzo de la muralla árabe", Catálogo de Monumentos y Conjuntos de la Comunidad Valenciana, Valencia, Consellería de Cultura de la Generalitat, vol. II, 1983, pp. 813-818.

2.680 - MASERES, M., "Orihuela. Sector antiguo de la ciudad", Catálogo de Monumentos y Conjuntos de la Comunidad Valenciana, Valencia, Consellería de Cultura de la Generalitat, vol. 1, 1983, pp. 649-665.

2.681 - MATEU LLOPIS, F., Alpuente reinio musulmán, Valencia, 1944.

2.682 - MELCHOR, F.; SEGUI, V.; PARICIO, F., Aproximació a la toponimia del País Valencià, València, 1978.

2.683 - MENÉNDEZ PIDAL, Ramón, "Murcia y Mortera, dos topónimos de origen indoeuropeon, Estudios de Lingüística, Madrid, 1970, pp. 7384. Análisis etimológico del topónimo "Murcia".

2.684 - MESADO, M., "Burriana. Casco urbano», Catálogo de Monumentos y Conjuntos de la Comunidad Valenciana, Valencia, Consellería de Cultura de la Generalitat. vol. I, 1983, pp. 225-241.

2.685 - MESTRE PALACIO, Joaquín, uHallazgo medieval en el centro urbano de Alcalalín, Crónica de la $\times$ Asamblea de Cronistas del Reino de Valencia, 1976, pp. 173-175

2.686 - MOLERES IBOR, Juan, Historia de Sollana, Valencia, 1982.

2.687 - MOLERES IBOR, Juan, "La torre de Trullás", Crónica de la X/I Asamblea de Cronistas del Reino de Valencia, 1980, pp. 101-110.

2.688-MOMBLANCH, Francisco de Paula, "Un cristiano de Alcoy redime a un esclavo moriscon, Alcoy. Revista de fiestas de moros y cristianos, Alcoy, 1980, pp. 91-92. Publicación de los documentos del fondo perteneciente a un morisco de Muro de Alcoy, hallados en el derribo de una casa de dicha población.

2.689 - MOMBLANCH Y GONZÁLEZ, Francisco de Paula, "Incorporación de Alicante, Elche, Orihuela y Guardamar al Reino de Valencian, IX Asamblea de Cronistas del Reino de Valencia, Valencia, 1974, 23 páginas.

2.690 - MONBLANCH Y GONZÁLEZ, Francisco de Paula, "Pergaminos de la Catedral de Valencia de los siglos XIII y XIV", Alcov. Revista de fiestas de moros y cristianos, Alcoy, 1974, pp. 31-32. Menciona la concesión a la Iglesia por parte de Jaime I de las mezquitas y cementerios musulmanes.

2.691 - MONTAGUT, Bernat, "Alcira. Conjunto histórico-artístico de la Villa", Catálogo de Monumentos y Conjuntos de la Comunidad Valenciana, Valencia, Conselleria de Cultura de la Generalitat, vol. I, 1983, páginas 115-128.

2.692 - MORENO ROYO, José María, Manises, retazos de su historia, Alcira, 1983. 


\section{N}

2.693 - NAVARRO AGUADO, Francisco, La Biblia en el Corán, Orihuela, Imp. Talleres Litográficos Lerón, 1978, $97 \mathrm{pp}$

2.694 - NAVARRO LÓPEZ, Genaro, Segura de la Sierra. Notas histórico-descriptivas de esta villa y su comarca, Segura de la Sierra, Ayuntamiento, $1965,227 \mathrm{pp}$

2.695 - NAVARRO VILLAPLANA, Hipólito, La fiesta de Moros y Cristianos de Petrer, Petrer, Ayuntamiento, 1983, 342 pp

2.696 - OSMA, G. J. de, "Los letreros ornamentales en la cerámica morisca española del s. XV", Cultura Española, Madrid, 1906.

2.697 - OSORIO, Antonio; PILES, Leopoldo; PIQUERAS, Juan, La villa de Requena. Una propuesta de rehabilitación, Valencia, Consellería de Cultura de la Generalitat-Ayuntamiento de Requena, 1982,87 pp.

\section{$\mathbf{P}$}

2.698 - PALAU GARCIA, F., "La situación histórica del marisco en el Reino de Valencia en el tránsito del siglo XVI-XVII», Hispania, Madrid, 149, 1981 , pp. 515-562.

2.699 - PECHE, Antonio, Breve reseña de Alfonso el Sabio y reconquista de Bullas, Caravaca, Imprenta Gonzalo de Haro y Martínez, 1982, 8 pp. Rendición de los musulmanes de Bullas a las tropas cristianas del Duque de Haro.

2.700 - PEREA, Agustín, La reconquista del castillo de Bullas, Murcia, Imprenta El Álbum, 1978, 24 pp. Narración de la conquista del citado castillo por el maestre de la Orden del Temple.

2.701 - PÉREZ MARTIN, Alfonso, "Murcia y la obra legislativa alfonsina: pasado y presenten, Congreso Internacional sobre Alfonso $X$ el Sabio: vida, obra, época, Madrid, 29 marzo/6 abril 1984, p. 62.

2.702 - PÉREZ I TOMÁS, Josep, "La fundació del Regne de València, zuna ruptura?», Eines, Alcoy, núms. 3 y 4, 1984, pp. 79-94.

2.703 - PÉREZ VILLANUEVA, Joaquín; ESCANDELL BONET, Bartolomé (editores), Historia de la Inquisición en España y América. I. El conocimiento científico y proceso histórico de la Institución (1478-1834), Madrid, B. A. C., 1984, 1.548 pp. Se desglosan los capítulos más relacionados con los musulmanes.

2.704 - PIGNON, Jean, Genes et Tabarca au XVIlème. siècle, Túnez. Universidad, 1980, $139 \mathrm{pp}$.

2.705 - PLA ALBEROLA, Primitivo, La población del marquesado de Guadalest en el siglo XVII, Alicante, Instituto de Estudios Alicantinos, 1983, $218 \mathrm{pp}$. Consecuencias de la expulsión de los moriscos. 
2.706 - POCKLINGTON, Robert, "Calpe, Cope y un grupo importante de nombres de montañas". Anales de la Universidad de Murcia. Filosofía y Letras, Murcia XXXVIII, 1981 (curso 1979-1980), pp. 237-248.

2.707 - POCKLINGTON, Robert, "Nuevos arabismos en los textos alfonsies murcianos" Miscelánea Medieval Murciana, Murcia, XI, 1984, páginas 263-295.

2.708 - POCKLINGTON, Robert, "Zaraíche", Anales de la Universidad de Murcia. Filosofia y Letras, Murcia, XXXVIII, 1981 (curso 1979-1980), pp. 249-254.

2.709 - POVEDA, Ángel, "Sobre los distritos, las explotaciones y la toponimia clánica de Yâbisa (EIVISSA), Shara Al-Andalus. Estudios Arabes, Alicante, núm. 1, 1984, pp. 109-117.

2.710 - POZO, 1.; FERNÁNDEZ, F.; MARIN RUIZ DE ASIN, D., "Sobre el topónimo yatțila de la Tarsi $i^{c}$ al Ajabar de Ahmad Al- ${ }^{\circ}$ Udri y su posible identificación con Celda", Anales del Colegio Universitario de Almería, Letras, Almería, 1981, pp. 133-139.

2.711 - PRETEL MARIN, Aurelio, "De realengo a Señorio: La villa de Chinchilla en la crisis alfonsí del trienio 1279-1282", Congreso Internacional sobre Alfonso $X$ el Sabio: vida, obra, época, Madrid, 29 marzo/6 abril 1984, p. 67

2.712 - PRETEL MARIN, Aurelio, Don Juan Manuel, señor de la llanura Irepoblación y gobierno de la Mancha albacetense en la primera mitad del siglo XIVI, Albacete, Instituto de Estudios Albacetenses, 1982, 296 páginas.

Q

2.713 - QUEROL, Jordi; MERCÉ, Moisés, Abans moros que catalans!, Valencia, ed. Tres i Quatre, 1984, 237 pp. Novela ficción histórico-política, de actualidad.

$\mathbf{R}$

2.714 - REGLÁ CAMPISTOL, J., Estudios sobre los moriscos, Barcelona, ed. Ariel, 1974.

2.715 - RIBERA, Albert; LERMA, Josep Vicent, «Panorámica de la arqueología urbana. Valencia romana e islámica", Revista de Arqueología, V, núm. 40, 1984, pp. 37-44.

2.716 - RIBERA Y TARRAGÓ, Julián, "Orígenes de la filosofia de Raimundo Lulion. Homenaje a Menéndez y Pelayo, Madrid, II, 1899, páginas 191-216.

2.717 - RIERA, Juan, Renta eclesiástica, moriscos y penitenciados (Los Obispados de Cartagena y Orihuela a mediados del siglo XVII, Valladolid, 1984. 
2.718 - RIU RIU, Manuel; PADILLA, José I., "La obra de Alfonso X, una fuente valiosa para la arqueología del siglo XII hispano: una nueva lectura arqueológica de las Cantigas", Congreso Internacional sobre Alfonso $X$ e/Sabio: vida, obra, época, Madrid, 29 marzo/6 abril 1984, páginas 70-71.

2.719 - RODRIGUEZ CAMPANILLO, Juan, "Cómo se desarrollaron las vivencias humanas en el Valle de Eldan, Alborada, Elda, septiembre 1984 pp. 41-44.

2.720 - RODRIGUEZ CULEBRAS, R., "Jérica. Casco Urbano", Catálogo de Monumentos y Conjuntos de la Comunidad Valenciana, Valencia, Consellería de Cultura de la Generalitat, vol. I, 1983, pp. 476-487.

2.721 - RODRIGUEZ CULEBRAS, R., "Jérica. Torre mudéjar llamada de la Alcudia o de las Campanas", Catálogo de Monumentos y Conjuntos de la Comunidad Valenciana, Valencia, Consellería de Cultura de la Generalitat, vol. 1, 1983, pp. 479-492.

2.722 - RODRIGUEZ CULEBRAS, R., "Segorbe. Casco antiguo", Catálogo de Monumentos y Conjuntos de la Comunidad Valenciana, Valencia, Consellería de Cultura de la Generalitat, vol. II, 1983, pp. 157-173.

2.723 - ROMÁN, J., "Bunyol. Castillo", Catálogo de Monumentos y Conjuntos de la Comunidad Valenciana, Valencia, Consellería de Cultura de la Generalitat, vol. 1, 1983, pp. 211-217.

2.724 - ROMÁN, J., "Chulilla. Castillo-fortaleza", Catálogo de Monumentos y Conjuntos de la Comunidad Valenciana, Valencia, Consellería de Cultura de la Generalitat, vol. I. 1983, pp. 369-377.

2.725 - ROMANY, J.; IVARS, J., Denia ¿qué y dónde?, Alicante, Gráficas Díaz, 1982, $62 \mathrm{pp}$.

2.726 - ROSSELLO VERGER, Vicenç M., "Notes toponímiques sobre el mapa de Mallorca del canonge Despuig", Quaderns de Filologia. Miscel.lània Sanchis Guarner, Valencia, 1, 1984, pp. 309-315. Rafais y alqueries de etimología árabe.

2.727 - RUBIERA DE EPALZA, María Jesús, Un benissero ilustre: el poeta árabe Ibn Al-Labbana, Benissa, Ayuntamiento (Papers de Benissa, Quaderns de Cultura Benissenca, núm. especial), 1984, 12 pp

2.728 - RUBIERA DE EPALZA, María Jesús, "Toponimia arábigo-valenciana: falsos antropónimos beréberesn, Quaderns de Filologia, Miscel/lània Sanchis Guarner, Valencia, 1, 1984, pp. 317-320.

2.729 - RUBIERA MATA, Maria Jesús, "Posible identificación de Ibn Al-Royôlo de Denia, ministro de Al-Muqtadir de Zaragoza (s. XI)" Sharq AlAndalus. Estudios Árabes, Alicante, núm. 1, 1984, pp. 147-151.

2.730 - RUBIERA MATA, Maria Jesús, "Rafals y reales; rabals y arrabales; reals y reales", Sharq Al-Andalus. Estudios Árabes, Alicante, núm. 1, 1984, pp. 117.123

2.731 - RUBiERA MATA, María Jesús, La Taifa de Denia, Alicante, Instituto de Estudios "Juan Gil Albert", 1985, $172 \mathrm{pp}$.

2.732 - RUBIO GARCIA, Luis, "Documentos sobre la estancia de San Vicente Ferrer en Murcian, Quaderns de Filologia. Miscellània Sanchis Guarner, Valencia, 1, 1984, pp. 321-325. En 1411. Reforzamiento de la legislación restrictiva contra los musulmanes. 
2.733 - RUBIO GARCIA, Luis, «Procedencia de los repobladores en el repartimento de Murcian, Congreso Internacional sobre Alfonso X el Sabio: vida, obra época, Madrid, 29 marzo/6 abril 1984, pp. 77-78.

2.734 - RULL VILLAR, Baltasar, "Aportación a un estudio sobre la convivencia hispano-árabe en el antiguo Reino de Valencia», Crónica de la IX Asamblea de Cronistas del Reino de Valencia, 1974, pp. 479-497.

\section{$\mathrm{S}$}

2.735 - SANCHEZ BUADES, Manuel; SALA SEVA, Federico, Resumen histórico de la villa de San Juan de Alicante. Alicante. Ayuntamiento de San Juan, $1978,270 \mathrm{pp}$.

2.736 - SÁNCHEŻ PÉAEZ, J., Biografias de matemáticos árabes que florecieron en España, Madrid, Academia de Ciencias Exactas, 1921

2.737 - SANCHIS ALFONSO, José Ramón, "La expulsión de los musulmanes y la nueva carta de población de Quart y Aldaya", Crónica de la XII Asamblea de Cronistas del Reino de Valencia, 1980, pp. 335-352.

2.738 - SASTRE MOLL, Jaime, "El castillo de Sent Agayz o La Almudaina de Mahón", Butlleti de la Socieiat Arqueológica Lul.liana, Palma de Mallorca, 40, 1984, pp. 331-336.

2.739 - SASTRE MOLL, Jaime, "Notas sobre la población musulmana menorquina a raiz de la conquista de Menorca por el rey Alfonso lll de Aragón". Curso Coloquio de Demografia Mediterránea, Menorca, Centro de Estudios Gabriel Alomar, 1984, 9 pp.

2.740 - SENIS DOMINGO, José, Serra, apuntes para su historia, Valencia, 1978.

2.741 - SESER, R., "Olocau. El Castell. Castillo de Alí Maimó», Catálogo de Monumentos y Conjuntos de la Comunidad Valenciana, Valencia, Conselleria de Cultura de la Generalitat, vol. I, 1983, pp. 587-598.

2.742 - SHATZMILLER, M., "Professions and Ethnic Origin of Urban Labouriers in Muslim Spain: Evidence from a Maroccan Source", Awraq, Madrid, núms. 5-6, 1982-83, pp. 149-161.

2.743 - SIMÓ, J. M. "Bocairent. Casco antiguo de la villa", Catálogo de Monumentos y Conjuntos de la Comunidad Valenciana, Valencia, Consellería de Cultura de la Generalitat, vol. I, 1983, pp. 202-210.

2.744 - SOLER GARCIA, José Maria, "Noticias sobre moriscos en el Archivo Municipal de Villena", Sharq Al-Andalus. Estudios Arabes, Alicante. núm. 1. 1984, pp. 71-91.

2.745 - SOTO, Ricardo, Codex catalá del Llibre del Repartiment de Mallorca, Barcelona, 1984.

2.746 - SOTO I COMPANY, Ricardo, "Mallorca, 1229-1302: del Repartiment a las Ordinacions", Historia de los pueblos de España. Vol. l. Los antiguos territorios de la Corona de Aragón, Barcelona, Argos Vergara, 1984; pp. 117-129. 
2.747 - TEIXIDOR, M. J., y otros, "Valencia. Valencia: conjunto histórico-artístico a favor de 6 zonas de la ciudad", Catálogo de Monumentos y Conjuntos de la Comunidad Valenciana, Valencia, Consellería de Cultura de la Generalitat, vol. II, 1983, pp. 225-342.

2.748 - TERÉS SÁDABA, Elías, "Literatura arăbigoespañola», en Islamología (dirigida por el P. Félix M. Pareja), Madrid, ed. Fax, 1952-54, páginas 979-998.

2.749 - TERÉS SÁDABA, Elías, "Literatura arábigoespañola», en Historia general de las literaturas hispánicas (dirigida por G. Diaz-Plaja), Barcelona, ed. Barna, vol. I, 1949, pp. 215-255.

2.750 - TORNERO POVEDA, Emilio, La disputa de los animales contra el hombre (fraducción del original árabe de la disputa del asno contra fray Anselmo Turmeda). Traducción, introducción y notas, Madrid, Universidad Complutense, 1984.

2.751 - TORRES BALBÁS, Leopoldo, "Los adarves de las ciudades hispanomusulmanas", Al-Andalus, Madrid, Crónica de la España musulmana núm. XX, pp. 164-193; Obra dispersa. I. Al-Andalus: Crónica de la España musulmana, Madrid, Instituto de España, 1/3, 1982, páginas 292-321. Mención del adarve (pasillo detrás de las almenas de los castillos) de Valencia.

2.752 - TORRES BALBÁS, Leopoldo, "Alcaicerias", Al-Andalus, Madrid, Crónica de la España musulmana, núm. XXV, pp. 431-455; Obra dispersa. 1. Al-Andalus: Crónica de la España Musulmana, Madrid, Instituto de España, 1/4, 1982, pp. 211-239. Mención de estos barrios mercantiles para productos especiales de Cuenca, Teruel, Zaragoza, Calatayud, Valencia, etcétera.

2.753 - TORRES BALBÁS, Leopoldo, "Algunos aspectos de la casa hispanomusulmana: almacerias, algorfas y saledizos», Al-Andalus, Madrid, Crónica de la España musulmana, núm. XXVI, pp. 179-191; Obra dispersa. I. Al-Andalus: Crónica de la España musulmana, Madrid, Instituto de España, 1/4, 1982, pp. 242-258. Mención de estas partes de las casas en el Repartiment de Valencia, y para otros lugares de Levante.

2.754 - TORRES BALBÁS, Leopoldo, "Almeria islámica", Al-Andalus, Madrid, XX11/2, 1957, pp. 411-453; Obra dispersa. I. Al-Andalus: Crónica de la España musulmana, Madrid, Instituto de España, 1/6, 1983, páginas 217-263.

2.755 - TORRES BALBÁS, Leopoldo, "Ampliación y tamaño de varias mezquitas", Al-Andalus, Madrid, XX1/2, 195.6, pp. 339-352; Obra dispersa. 1. Al-Andalus: Crónica de la España musulmana, Madrid, Instituto de España, 1/6, 1983, pp. 78-91. Referencia a la mezquita de Zaragoza, como una de las primeras hechas en España, $v$ a la de Almería.

2.756 - TORRES BALBÁS, Leopoldo, "El arte mudéjar en Aragón", Al-Andalus, Madrid, V/2, 1940, pp. 190-192; Obra dispersa. I. Al-Andalus: Crónica de la España musulmana, Madrid, Instituto de España, 1/1. 1981, pp. 207-209. 
2.757 - TORRES BALBÁS, Leopoldo, "Atarazanas hispanomusulmanas", A/Andalus, Madrid, XVIII/1, 1953, pp. 175-209; Obra dispersa. I. AlAndalus. Crónica de la España musulmana, Madrid, Instituto de España, 1/3, 1982, pp. 130-172. Menciona varios astilleros del Sharq AlAndalus: Pechina, Denia, Tortosa, Mallorca y Barcelona.

2.758 - TORRES BALBAS, Leopoldo, "Bâb al-Sudda y las zudas de España oriental», Al-Andalus, Madrid, XVIl/1, 1952, pp. 165-175; Obra dispersa. I. Al-Andalus: Crónica de la España musulmana, Madrid, Instituto de España, |/5, 1982, pp. 75-85. Mención del alcázar-palacio señorial, o zuda, de la Albufera (cerca de la confluencia del Júcar y el Huécar), Calatayud, Tarazona, Zaragoza, y otras del Sharq AlAndalus.

2.759 - TORRES BALBAS, Leopoldo, "El baño de Torres (Valencia) y otros levantinos", Al-Anda/us, Madrid, XVII/1, 1952, pp. 176-186; Obra dispersa. 1. Al-Andalus: Crónica de la España musulmana, Madrid, Instituto de España, //5, 1982,pp. 86-98. Estudio de baños de Murviedro (hoy Sagunto), Játiva, Alcira y Chinchilla.

2.760 - TORRES BALBÁS, Leopoldo, "Barbacanas", Al-Andalus, Madrid, XVI/2, 1951, pp. 454-480; Obra dispersa. I. Al-Andalus: Crónica de la España musuimana, Madrid, Instituto de España, 1/5, 1982, páginas 46-74. Barbacanas (muralla secundaria antepuesta a la principal de la ciudad) de Valencia, Mallorca, Tortosa, Murcia y Almería en el Levante peninsular.

2.761 - TORRES BALBAS, Leopoldo, "Bóvedas caladas hispanomusulmanas", Al-Andalus, Madrid, XVII/1, 1952, pp. 186-199; Obra dispersa. I. Al-Andalus: Crónica de la España musulmana, Madrid, Institu to de España, $1 / 5,1982$, pp. 98-119. Describe las de la Aljafería de Zaragoza, Mezquita de Córdoba, y sus influencias posteriores en el arte gótico y renacentista.

2.762 - TORRES BALBÁS, Leopoldo, "La judería de Zaragoza y su baño", A/Andalus, Madrid, XXV11, 1956, pp. 172-190; Obra dispersa. I. A/Andalus: Crónica de la España musulmana, Madrid, Instituto de España, 1/6, 1983, pp. 56-77.

2.763 - TORRES BALBÁS, Leopoldo, "La mezquita mayor de Almería", Al-Andalus, Madrid, XVIII/1, 1953, pp. 412-430; Obra dispersa, I. A/Andalus: Crónica de la España musulmana, Madrid, Instituto de España, $1 / 5,1982$, pp. 249-276.

2.764 - TORRES BALBÁS, Leopoldo, "Mușallà" y "šar "č s" en las ciudades hispanomusulmanas", Al-Andalus, Madrid, Crónica de la España musulmana, núm. XXII, pp 167-180; Obra dispersa. I. Al-Andalus: Crónica de la España musulmana, Madrid, instituto de España, 1/4, 1982, pp. 85-98. La "musallà" (mezquita al aire libre en descampados fuera de las ciudades, para fiestas especiales) de Valencia y Almería.

2.765 - TORRES BALBÁS, Leopoldo, "Patios de crucero", Al-Andalus, Madrid, XXIll/1, 1958, pp. 171-191; Obra dispersa. I. Al-Andalus: Crónica de la España musulmana, Madrid, Instituto de España, I/6, 1983, pp. 300-322. Estudio comparativo de varias plantas de crucero en edificios musulmanes, entre ellas la del Castillejo de Monteagudo (Murcia). 
2.766 - TORRES BALBÁS, Leopoldo, "Rábitas hispanomusulmanas», AlAndalus, Madrid, Crónica de la España musulmana núm. XXIII, pp. 475-491; Obra dispersa. I. Al-Andalus: Crónica de la España musulmana, Madrid, Instituto de España, 1/4, 1982, pp. 158-174. Mención de estos "monasterios" musulmanes de: Denia, Bairén, Villanueva del Grao, Valençia, San Carlos de la Rápita, Cartagena y las de Baleares,

2.767 - TORRES BALBÁ, Leopoldo, "El taller de marfiles de Cuenca", A/Andalus, Madrid, Crónica de la España musulmana, núm. III, pp. 396-397; Obra dispersa. I. Al-Andalus: Crónica de la España musulmana, Madrid, Instituto de España, 1/1, 1981, pp. 74-75.

2.768 - TORRES BALBAS, Leopoldo, "Las yeserías descubiertas recientemente en Las Huelgas de Burgos", Al-Andalus, Madrid, Crónica de la España musulmana, núm. XII, pp. 209-254; Obra dispersa. I. Al-Andalus: Crónica de la España musulmana, Madrid, Instituto de España, I/2, 1982, pp. 184-237. Estudio comparativo con otras yeserías conocidas, como algunas de Murcia, Almería y Játiva.

2.769 - TORRES CREMADES, Joan Antoni, "Bellreguart», Ullal, Gandía, número 2,1982, pp. 62-64. Etimologias árabes, refutadas en el artículo de Carmen Barceló.

2.770 - TORRES FONTES, Juan, "La caballería del alarde murciana en el siglo XVn, Anuario de Historia del Derecho Español, Madrid, XXXVIII, 1968, pp. 31-86. Disposiciones reales otorgadas al Reino de Murcia para desarrollar esta caballería ciudadana, y evolución hasta su disolución con el fin de la guerra de Granada

2.771 - TORRES FONTES, Juan, "Conquista castellana y pérdida de Albox en el reinado de Juan $\|$ (1436-1445), Roel, Albox, núm. 1, 1980, páginas 35-42. Avances y retrocesos de la frontera murciano-granadina con las guerras.

2.772 - TORRES FONTES, Juan, "La cultura murciana en el reinado de Alfonso X", Murgetana, Murcia, 14, 1960, pp. 57-90. Gran auge cultural que significa su reinado, en el que vemos sabios musulmanes como Al-Ricoti $y$ otros.

2.773 - TORRES FONTES, Juan, "Un diezmo eclesiástico en Sevilla y Murcia (siglo XIII)m, Congreso Internacional sobre Alfonso X el Sabio: vida, obra, época..., Madrid, 29 marzo/6 abril de 1984, pp. 84-85. Para las guerras contra los musulmanes.

2.774 - TORRES FONTES, Juan, Documentos para la Historia Medieval de Cehegín, Murcia, Academia Alfonso X el Sabio, 1982, $231 \mathrm{pp}$.

2.775 - TORRES FONTES, Juan, "Dos fechas de España en Murcia", Anales de la Universidad de Murcia. Facultad de Filosofia y Letras, Murcia, VI, 1945-46, pp. 641-648. Procesiones en Murcia al conocer la toma de Granada.

2.776 - TORRES FONTES, Juan, "Fueros y privilegios de Alfonso $X$ el Sabio al Reino de Murcia, Murcia, Academia Alfonso Xel Sabio, Il, 1973, LXI más $184 \mathrm{pp}$. Recopila 95 documentos otorgados a Murcia entre $1245 \vee 1283$. 
2.777 - TORRES FONTES, Juan, "Murcia en el s. XIV", Actas del/ Simposio de Historia Medieval: la investigación de la historia hispánica del s. $X I V$. Problemas y cuestiones, Madrid-Barcelona, 1973; y en Anuario de Estudios Medievales, Ba.celona, 7, 1970-71, pp. 253-277.

2.778 - TORRES FONTES, Juan, "Dos ordenamientos de Enrique II para los caballeros de cuantía de Andalucía y Murciam. Anuario de Historia del Derecho Español, Madrid, XXXIV, 1964, pp. 463-478. Disposiciones para los reinos fronterizos de Granada para el mantenimiento de una caballería.

2.779 - TORRES FONTES, Juan, El poblamiento murciano en el siglo XIII, Murcia, Academia Alfonso $X$ el Sabio, 1962, 15 pp.

2.780 - TORRES FONTES, Juan; CALVO GARCIA-TORNEL, Francisco, "Política y geografia; la delimitación del Reino de Murcia en la Edad Media», Congreso Internacional sobre Alfonso $\times$ el Sabio: vida, obra, época, Madrid, 29 de marzo/6 abril 1984, pp. 86-87.

2.781 - TORRES FONTES, Juan; VEAS ARTESEROS, Francisco, "Procedencia de los repobladores en el repartimento de Orihuela", Congreso Internacional sobre Alfonso X el Sabio: vida, obra, época, Madrid, 29 marzo/6 abril 1984, pp. 88.

2.782 - TORRES FONTES, Juan, «La regencia de don Fernando el de Antequera y las relaciones castellano-granadinas (1407-1416)", Miscelánea de Estudios Árabes y Hebraicos, Granada, Universidad, vols. 14, $15,16,17,21$ y 22 de 1965, 1966, 1967, 1968, 1972 y 1973. Análisis de campañas y treguas granadinas en territorio murciano y de la actividad del regente castellano frente al reino nazarí.

2.783 - TORRO IABAD, Josep, "Arqueología medieval de Alcoi y su entorno", Alcoy. Prehistoria y Arqueología. Cien años de investigación, Alcoy, Ayuntamiento de Alcoy/Instituto "Juan Gil Albert", 1984, páginas 277-309.

2.784 - TURKI, Abdel Magid, Théologiens et juristes de l'Espagne musulmane: Aspects polémiques, París, Maisonneuve et Larose, 1982, 372 páginas.

2.785 - TYAN, Emile, Histoire de /'organisation judiciaire en pays d'slam, Leiden, E. J. Brill, 1960,673 pp.

$\bigcup$

2.786 - UBIETO ARTETA, Antonio, Toponimia aragonesa medieval, Valencia, ed. Anubar, 1972.

2.787 - URVOY, Dominique, Elmundo de los ulemas andaluces del siglo VIXI al VIIIXIII, Madrid, 1983.

\section{V}

2.788 - VALDÉS PERLASIA, Emilio, "Onil. Datos hiștóricos de la villa y su palacion, Moros y Cristianos, Onil, 1970. Datos y fuentes de la conquista cristiana. 
2.789 - VALERO IVÁÃEZ, Manuel, “El Norte de África en la documentación del Consulado francés en Alicante durante el siglo $X \mid X_{*}$, Anales de Historia Contemporánea, Madrid-Orihuela, 3, 1984, pp. 245-254.

2.790 - VALLS TABERNER, Fernando, Los privilegios de Alfonso X a la ciudad de Murcia, Barcelona, Tip. Católica Casals, 1923, 82 pp.

2.791 - VALOR, Gloria de, "Apuntes sobre la Orden del Temple en el origen de las fiestas de moros y cristianos". Alcoy. Fiestas de Moros y Cristianso, 1 982, p. 112. Participación de la Orden del Temple en las luchas con los musulmanes en tierras alcoyanas.

2.792 - VAÑO SILVESTRE, Francisco, "Dos documentos sobre niños abandonados", Crónica de la X Asamblea de Cronistas del Reino de Valencia, 1976, pp. 137-147.

2.793 - VARELA, Santiago; CALDUCH, Joan, Rutes d'aproximació al patrimoni cultural valencià: Alacant-Tabarca, Valencia, Capitanía General de la Ill Región Militar/Consellería de Cultura de la Generalitat, 1983. 75 páginas.

2.794 - VARELA, Santiago, "Villena. Sector antiguo de la ciudad", Catálogo de Monumentos y Conjuntos de la Comunidad Valenciana, Valencia, Consellería de Cultura de la Generalitat, vol. II, 1983, pp. 861-876.

2.795 - VENTURA, Agustí, "Noms de carrers de Xàtiva", Xàtiva. Fira d'Agost, 1980, Játiva, 1980, pp. 21-32. Toponimia menor de origen árabe.

2.796 - VENTURA, Agustí, "Privilegi de població otorgat pel rei En Jaume als Serrains pobladors del raval de Xàtiva. Gener de 1251 ", Xàtiva. Fira d'Agost, 1979, Játiva, 1979, pp. 85-88. Traducción del latín y comentarios.

2.797 - VENTURA I SUBIRATS, Jördi, Inquisició Espanyola i Cultura Renaixentista al País Valencià, Valencia, Eliseu Climent, 1978, 204 pp.

2.798 - VERNET, Juan, «El pensamiento científico en Al-Andalus: medio siglo de historia de la ciencia árabe en Al-Andalus", Revista del Instituto Egipcio de Estudios /slámicos, Madrid, XXII, 1983-84, pp. 7-20. Especialmente sobre la Cataluña medieval pirenaica y los estudios actuales sobre ciencia árabe en Barcelona.

2.799 - VERNET, Juan, Estudios sobre historia de la ciencia árabe, Barcelona, C. S. I. C., 1980, 315 pp.

2.800 - VERNET, Juan, Textos y estudios sobre astronomía española en el siglo XIII, Barcelona, Universidad Autónoma, 1981, 323 pp

2.801 - VERNIA MARTÍNEZ, Pedro, La farmacopea valenciana y los Fueros del Reino de Valencia, Alicante, Asociación Defensora de los Intereses Alicantinos, 1982

2.802 - VETGES TU I MEDITERRÀNIA, "Llutxent. Conjunto formado por el Castillo de los Moros, Iglesia-convento del Corpus Cristi y Ermita de la Consolación", Catálogo de Monumentos y Conjuntos de la Comunidad Valenciana, Valencia, Consellería de Cultura de la Generalitat, vol. I, 1983, pp. 504-520.

2.803 - VIDAL BELTRAN, Eliseo, Abù 'Ubayd Al-Bakri: Geografía de España (Kitâb al-Masâlik wa-l-mamálik), Zaragoza, ed. Anúbar, 1982, $58 \mathrm{pp}$. 
2.804 - VILA MORENO, Alfonso, Aproximación a la historia de Canals, Canals, 1980.

2.805 - VILA MORENO, Alfonso, "De Benitaro a Torre de Cerdá", Cronicó del Regne de València, octubre-desembre 1980 i any $1981, n .^{\circ} 11$ 12 , p. 8 .

2.806 - VILA MORENO, Alfonso, "Los cronistas y la temática morisca», Cronicó del Regne de València, VII/20-21, 1984, pp. 14-15.

2.807 - VILAPLANA GISBERT, José, Historia religiosa de Alcoy, Alicante, Diputación Provincial, 1977, 525 pp. Expansión de la lglesia en Alcoy tras la conquista, $y$ sus roces con moros y moriscos.

2.808 - VILAR, Juan Bautista, "El arabista Pascual de Gayangos en los orígenes de la ciençia numismática española. Su viaje a París y Londres en 1835", Sharq A/-Andalus. Estudios Arabes, Alicante, núm. 1, 1984. pp. $161-167$.

2.809 - VILAR, Juan Bautista, "La rebelión y dispersión de los moriscos: el casco murcianon, Historia de la inquisición en España y América, Madrid, vol. I, B. A. C., 1984, pp. 772-780. 